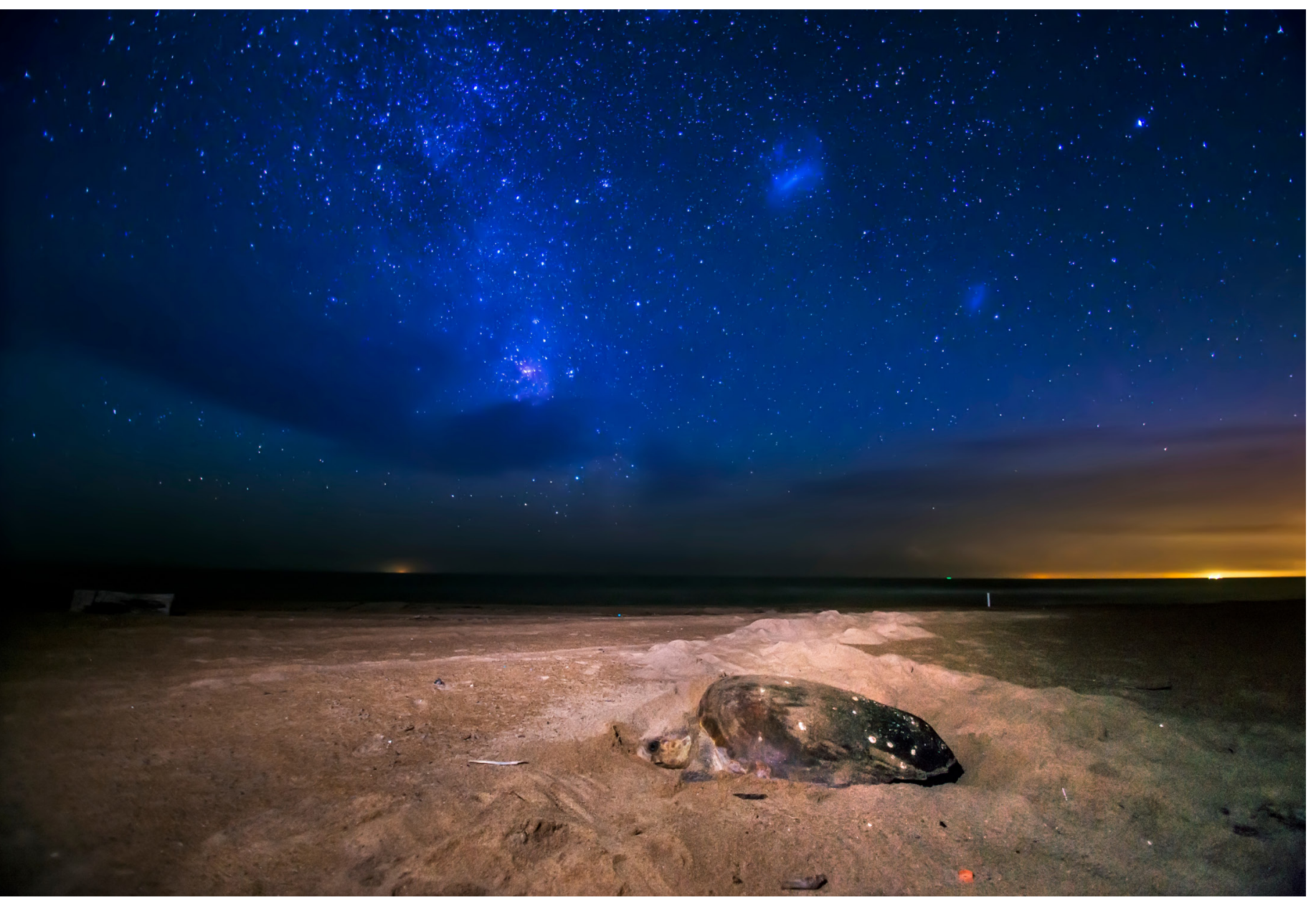




\section{Educação Patrimonial e Fotografia: O Projeto Clic@R Itapina e o Resgate da Memória Local}

Patrimonial Education And Photography: The Clic@R litapina Project and the Rescue of The Local Memory

\section{Resumo}

Analisa as ações de educação patrimonial utilizando fotografias de acervos pessoais, como linguagem artística, para expressar as manifestações culturais de uma comunidade, com o objetivo de verificar sua relação com o sentimento de pertencimento à história local e com a valorização do seu patrimônio cultural. A abordagem do problema se deu por meio de pesquisa quantitativa (instrumentos estatísticos) e qualitativa, utilizando-se a dedução como método de investigação para avaliar a efetividade das ações para a sociedade. Apurou-se que a oficina de educação patrimonial apresentou conteúdo relevante e que seus produtos causaram impactos socioculturais positivos. Concluiu-se que a metodologia de educação patrimonial aplicada pela equipe do projeto Clic@r Itapina foi eficiente para o propósito de despertar o sentimento de pertencimento e foi uma forma de valorizar a cultura local. A hipótese também foi confirmada, pois quanto mais se disponibilizou o acesso às fotografias, mais sentimentos afetivos foram despertados, trazendo boas lembranças. Em análise final, verificou-se que o conteúdo informacional das fotografias remete ao sentimento de pertencimento e à valorização do patrimônio cultural.

Palavras-chave: Patrimônio Cultural; Educação Patrimonial; Fotografia; Acervos Pessoais. 


\section{Abstract}

It analyzes heritage education actions using photographs of personal collections as artistic language to express the cultural manifestations of a community, with the purpose of verifying their relationship with the feeling of belonging to the local history and with the appreciation of their cultural patrimony. The approach of the problem occurred through quantitative research (statistical instruments) and qualitative, using deduction as a research method to evaluate the effectiveness of actions for society. It was found that the patrimonial education workshop presented relevant content and that its products caused positive socio-cultural impacts. It was concluded that the patrimonial education methodology applied by the Clic@r Itapina project team was efficient for the purpose of awakening the sense of belonging and was a way to value the local culture. The hypothesis was also confirmed, because the more the access to the photographs became available, the more affective feelings were aroused, bringing good memories. In the final analysis, it was verified that the information content of the photographs refers to the feeling of belonging and to the appreciation of cultural heritage.

Keywords: Cultural Heritage; Patrimonial Education; Photography; Acervos Personalais. 


\section{INTRODUÇÃO}

Itapina, um distrito localizado a 25 km de Colatina, no Espírito Santo, foi fundado em meados do século XIX por imigrantes europeus e, atualmente, possui cerca de três mil habitantes, sendo que desses, apenas 30\% residem no perímetro urbano da localidade. Este distrito teve seu auge em meados de 1910, quando foi um dos polos comerciais de café mais rico do Espírito Santo. Durante a década de 1970, entrou em decadência devido a um conjunto de fatores, como o declínio da produção de café, a ponte inacabada e ao êxodo rural, que fizeram com que grande parte de seus moradores se mudassem para cidades maiores, como Vitória e Colatina, em busca de melhores perspectivas de vida. Gradativamente os bares, clubes, meios de entretenimento, fábricas e até a escola particular foram fechados por inviabilidade econômica.

Atualmente, é considerada patrimônio de interesse público, porque possui oficialmente, por meio da Resolução do Conselho Estadual de Cultura no 003/2013, que aprovou o Tombamento do Conjunto Histórico e Paisagístico de Itapina reconhecido valor cultural - aquele atribuído ao patrimônio cultural das cidades, abrangendo elementos formadores da identidade de determinado lugar, articulando o patrimônio arquitetônico, o traçado urbano, a paisagem, seus valores históricos, sociais, culturais, técnicos, formais, afetivos e as inter-relações entre eles.

Trata-se de um local que foi palco de significativos acontecimentos históricos e de grande importância para o estado do Espírito Santo, guarda elementos formadores da identidade da comunidade, que, em diferentes épocas, conviveu e manteve relações com o patrimônio arquitetônico, o traçado urbano, a paisagem, desenvolvendo valores socioculturais e afetivos.

Nesse contexto, insere-se o conceito de "Patrimônio Cultural", que é toda e qualquer manifestação material ou imaterial que um povo ou uma comunidade cria e acumula ao longo dos anos e "está presente em todos os lugares e atividades: nas ruas, em nossas casas, em nossas danças e músicas, nas artes, nos museus e escolas, igrejas e praças, nos modos de fazer, criar e trabalhar" (IPHAN, 2013). Sendo assim, não somente os acontecimentos históricos, mas também os múltiplos aspectos da cultura viva devem ser alvo de ações que visem ao registro e à preservação para gerações futuras.

São todas as manifestações e expressões que a sociedade e os homens criam e que, ao longo dos anos, vão se acumulando com as das gerações anteriores. Cada geração as recebe, usufrui delas e as modifica de acordo com sua própria história e necessidades. Cada geração dá a sua contribuição, preservando ou esquecendo essa herança. (GRUNBERG, 2007).

No entanto, para que a população local pudesse de fato usufruir e sentir-se parte desse patrimônio, foram realizadas, por meio do Projeto Clic@r Itapina, ações

No governo de Juscelino Kubitschek, dentro do Plano de Metas estava incluído um projeto de uma ponte que passaria sobre o Rio Doce eligarialtapina à então emarian enconstruçấ, BR-101 e encurtaria o caminho até Colatina em até 30 minutos. Devido à falta de interesses políticos eà burocracia, a ponte foi abandonada e atualmentevirou umponto turistico da cida un ponto com a erradicação do café que teve inicio na década de 1960, Itapina ainda resistiu a decadência, principalmente por seu forte comércio, sustentado pelos donos propriedades rurais. 
de educação patrimonial com vistas a restabelecer os laços de identidade entre os moradores e seu próprio patrimônio, tornando-o, efetivamente, um conjunto de bens compartilhados por todos.

Clic@r Itapina foi um projeto cultural de extensão universitária realizado pelo Grupo de Pesquisa Archivum - Sociedade, Informação e Cultura, do Departamento de Arquivologia da Universidade Federal do Espírito Santo (UFES), que utilizou recursos do Fundo Estadual de Cultura do Estado do Espirito Santo (FUNCULTURA), da Secretaria da Cultura do Estado do Espírito Santo (SECULT), por ter sido um dos contemplados no processo seletivo referente ao Edital de Seleção de Projetos Culturais de Educação Patrimonial no 13/2015, que foi publicado visando a apoiar projetos que oportunizem a promoção da educação patrimonial, visando a preservação e proteção do patrimônio arquitetônico, natural, ecológico, paisagístico e arqueológico.

O projeto consistiu na realização de oficinas de educação patrimonial compostas de palestras, curso teórico, pesquisas e atividades práticas, de forma gratuita e aberta à comunidade, visando a resgatar a memória local, utilizando os registros fotográficos pessoais e de familiares como linguagem artística e pedagógica para abordar o tema patrimônio cultural.

A fotografia também desempenha papel fundamental na lembrança. Fotos antigas relembram momentos importantes, passagens antigas do cotidiano, auxiliando no entendimento de como era antes e de como é atualmente. Elas mostram diferenças de épocas, semelhanças dos costumes que persistem, modos e valores de outros tempos, locais que não existem mais ou continuam os mesmos e assim por diante (CASTIGLIONI, 2010).

Nesse contexto, a pesquisa visa responder ao seguinte problema: como implementar ações de educação patrimonial utilizando fotografias para despertar o sentimento de pertencimento da comunidade e valorizar a cultura local?

A hipótese é que quanto mais relembrados são os fatos por meio de fotografias, mais aumenta o sentimento de pertencimento à história retratada e a valorização desse patrimônio cultural, dessa forma, proporcionando o sentimento de entendimento do indivíduo com agente transformador de seu meio e de sua própria realidade. Neste estudo, analisaremos por meio de dados quantitativos e qualitativos se há indícios de que o sítio histórico de Itapina e sua comunidade, inclusive os Itapinenses ausentes, receberam benefícios das ações de extensão por meio da educação patrimonial, sob a linguagem fotográfica.

Nesse sentido, o objetivo principal da pesquisa é analisar se o consumo dos bens culturais retratados em fotografias tem relação com o sentimento de pertencimento da comunidade com a história local e com a valorização e visibilidade do patrimônio cultural do sítio histórico de Itapina. 
Para alcançar este objetivo, pretende-se: 1) compreender a comunidade em sua importância cultural e patrimonial; 2) realizar abordagens sobre os acervos pessoais como fonte de pesquisa; 3) refletir sobre a construção da consciência de preservação, conservação e valorização desses bens culturais; 4) perceber as dimensões tangíveis e intangíveis dos bens culturais da comunidade, incluindo acervos pessoais, produção de registros documentais inéditos e o universo de práticas de memória envolvido na sua constituição e; 5) verificar as contribuições dos acervos fotográficos para a formação da identidade cultural e para a conscientização sobre a proteção e preservação do patrimônio cultural do sítio histórico de Itapina. Considerando as oficinas e os produtos do projeto Clic@r Itapina, verificou-se um público-alvo formado por estudantes de ensino fundamental, médio, superior e de pós-graduação; pesquisadores e profissionais na área da história, comunicação, artes, ciências sociais, dentre outros; além de moradores de todas as idades do distrito de Itapina, de turistas e visitantes.

Esse resgate histórico é de interesse público e promove o desenvolvimento cultural, além de preencher lacunas e suprir carências informacionais sobre a história local, pois, geralmente, essas informações não se encontram disponíveis em centros de memória institucionalizados, mas, sim, nas lembranças e em acervos pessoais. Estes foram os motivos pelos quais se justificou a realização do projeto.

As oficinas do projeto Clic@r Itapina foram realizadas entre os meses de fevereiro e maio de 2016, na Escola Municipal de Ensino Fundamental "Maria Ortiz", localizada Rua Galdêncio Souza, 83, no sítio histórico de Itapina e sua metodologia desenvolveuse por meio de aulas teóricas e de campo que ensejaram o contato e a participação da comunidade.

\section{O patrimônio documental como bem material da sociedade}

Patrimônio é uma palavra de origem latina, patrimonium, que se referia, entre os romanos da antiguidade, a tudo que pertencia ao pai, pater ou pater famílias. Nesse caso, a família compreendia tudo que pertencia ao senhor, inclusive filhos, mulheres, escravos e até mesmo os animais, incluindo, obviamente, os bens móveis e imóveis.

Importante destacar que o conceito de patrimônio surge no âmbito do interesse aristocrático e privado. Sendo assim, até a idade contemporânea não existia o conceito de patrimônio público nos termos que entendemos hoje. Cabe destacar que a ideia de patrimonializar bens culturais somente ganhou relevância no decorrer do século XIX, principalmente, com a Revolução Francesa e após os processos de organização dos Estados nacionais modernos e a construção da ideia de nação.

Durante muitos séculos de evolução histórico-jurídica da proteção estatal dos arquivos, a utilização dos seus documentos era privilégio de sábios, monges e reis. Durante a Idade Antiga, toda a Idade Média e parte da Idade Moderna, o direito à informação não se baseava em princípios legais universais, mas atendiam aos 
interesses aristocráticos e particularmente da realeza (MATTAR, 2003, p.22). Desde os primórdios da civilização, o homem se preocupou em preservar documentos de sua vida econômica, política, social, administrativa e religiosa. Algumas transformações acompanharam a humanidade no que concerne ao acesso a esses documentos de arquivo, bem como o conceito de patrimônio cultural.

Na Antiguidade Clássica, o acesso aos arquivos estava restrito aos representantes do poder e a um reduzido grupo de eruditos bem relacionados com as elites políticas. Durante a Idade Média, a Igreja controlou a cultura e a preservação de documentos concentrados em conventos e mosteiros. Na Idade Moderna, com o absolutismo monárquico, a organização dos arquivos passou a ser "um conjunto de armas políticas e jurídicas a serviço dos Reis” (RICHTER, 1997, P. 18).

A prática arquivística nessa fase histórica era o sigilo documental e o acesso aos arquivos era autorizado a poucas pessoas. Após a Revolução Francesa, avançouse para uma nova concepção no que diz respeito à administração de arquivos. Nessa época, permitiu-se que investigadores tivessem acesso aos documentos e fez-se divisão entre arquivos históricos e administrativos (CRUZ MUNDET, 2001, p.30).

Com a Declaração dos Direitos do Homem e do Cidadão, em 1789, o acesso aos arquivos passa a ser um direito de todos acompanhar a administração do Estado, pelo menos teoricamente. Contudo, a valorização dos arquivos administrativos vai ganhar maior importância com a crise econômica dos EUA, a partir de 1929, e vai consolidar-se com a Segunda Grande Guerra.

Com a Guerra Fria, União das Repúblicas Socialistas Soviéticas (URSS) e EUA, as duas grandes potências da época, passam a reconhecer a importância administrativa de seus arquivos, fundamentais para o bom andamento da economia. O mundo ocidental começa a considerar essas questões após a aprovação da Convenção do Patrimônio Mundial, Cultural e Natural, pela Organização das Nações Unidas para Educação, Ciência e Cultura (UNESCO), em 1972, quando países do Terceiro Mundo pleitearam também, junto a essa organização, um instrumento internacional para a proteção às manifestações populares de valor cultural.

A resposta viria em 1989, por meio da Recomendação sobre a Salvaguarda da Cultura Tradicional e Popular, que orienta os países membros:

A identificação, a salvaguarda, a conservação, a difusão e a proteção da cultura tradicional e popular, por meio de registros, inventários, suporte econômico, introdução do seu conhecimento no sistema educativo, documentação e proteção à propriedade intelectual dos grupos detentores de conhecimentos tradicionais passa a ser uma obrigação do Estado e direito universal do cidadão.

Para Max Weber (1982, p.265), os documentos são os instrumentos de produção da burocracia do Estado. Em 1789 foi criado o Arquivo Nacional Francês; no Brasil, foi criado o Arquivo Nacional, em 1838. Observamos uma ampla preocupação 
da sociedade com as instituições ligadas à preservação da memória. Essa nova realidade é acompanhada de uma preocupação internacional, nacional e local com a criação de leis que protegessem o patrimônio documental em comum.

No Brasil, durante muito tempo, manteve-se um conceito restrito e tradicional de patrimônio histórico e cultural relacionando-o à prática da preservação de monumentos. O direito público brasileiro data da independência, com o ato de criação do Arquivo Nacional que teve, como finalidade principal, a legitimação do Estado e a construção da identidade cultural nacional. Tal situação criou a ideia de que as políticas relacionadas ao patrimônio cultural eram elitistas, uma vez que os critérios terminavam por privilegiar os grupos sociais identificados com as classes dominantes (FONSECA, 2003, p.74).

A noção no país de que o patrimônio cultural não se resume às edificações arquitetônicas e obras de arte, remonta à figura de Mário de Andrade, pioneiro do registro dos aspectos imateriais do patrimônio cultural brasileiro. O anteprojeto que o poeta modernista elaborou para o Serviço de Patrimônio Histórico e Artístico Nacional (SPHAN), em 1936, apesar de revolucionário, não chegou a ser codificado em termos legais.

Contudo, logo depois, durante o Estado Novo, Getúlio Vargas assina, em 1937, o Decreto-lei no 25, no qual o artigo primeiro declara que:

Constitui Patrimônio Histórico e Artístico Nacional o conjunto dos bens móveis e imóveis existentes no país e cuja conservação seja de interesse público, quer por sua vinculação a fatos memoráveis da História do Brasil, quer por seu excepcional valor arqueológico e etnográfico, bibliográfico e artístico.

Assim, foi reconhecido o direito de toda pessoa em participar da vida cultural do seu país e a gozar dos benefícios do progresso científico e de suas aplicações, recomendando-se ao Estado medidas necessárias à conservação, ao desenvolvimento e à difusão da ciência e da cultura.

A Constituição Brasileira de 1988, promulgada pelo então Presidente José Sarney, além de oficializar a responsabilidade do Estado, em seu artigo 216, considera como patrimônio cultural:

[...] os bens de natureza material e imaterial, tomados individualmente ou em conjunto, portadores de referência à identidade, à ação, à memória dos diferentes grupos formadores da sociedade brasileira, nos quais se incluem:

I - as formas de expressão;

II - os modos de criar, fazer e viver;

III - as criações científicas, artísticas e tecnológicas;

IV - as obras, objetos, documentos, edificações e demais espaços destinado às manifestações artístico-culturais; [grifo nosso]
O Instituto do Patrimônio OInstituto do Património
Historico e Artístico Nacional (IPHAN) foi precedido pelo Serviço do Patrimônio Histórico e Artístico Nacional (SPHAN) criado em 13 de janeiro de 1937 e regulamentado pelo Decreto-Lei no 25 no dia 30 de novembro do mesmo ano, poucos dias após o golpe que instituiu o Estado Novo. 
$V$ - os conjuntos urbanos e sítios de valor histórico, paisagístico, artístico, arqueológico, paleontológico, ecológico e científico.

A principal contribuição da Constituição de 1988 foi a ampliação do conceito de patrimônio, pois incluiu os bens de natureza referentes "[...] à identidade, à ação, à memória dos diferentes grupos formadores da sociedade brasileira”.

Sem dúvida, ao lado dessa evolução histórico-jurídica da proteção dos documentos de arquivo e do conceito de patrimônio cultural, aparece, também, a luta da sociedade folclorista, dos movimentos negros e indígenas, de descendentes de imigrantes de várias procedências, entre outros. O resultado dessa caminhada é o decreto 3551/2000, assinado pelo então Presidente da República Fernando Henrique Cardoso, instituindo o registro de bens culturais de natureza imaterial constituidores do patrimônio cultural brasileiro. Essa nova concepção de patrimônio cultural amplia significativamente o leque de saberes e de instituições envolvidas com a gestão e promoção desse patrimônio, ou seja,

A ampliação do conceito de cidadania, o que implica reconhecimento dos 'direitos culturais' de diferentes grupos que compõem uma sociedade, entre eles o direito à memória, ao acesso à cultura e à liberdade de criar, como também reconhecimento de que produzir e consumir cultura, são fatores fundamentais para o desenvolvimento da personalidade e da sociabilidade, veio contribuir para que o enfoque da questão do patrimônio cultural fosse ampliado para além da questão do que é 'nacional', beneficiando-se do aporte de compor com a Antropologia, a Sociologia, a Estética e a História. (FONSECA, 2003, p. 74)

Dessa forma, se estabelece elo indissociável entre os documentos de arquivo e a cultura, reconhecendo o direito de todos a participarem da vida cultural. Além disso, a Constituição de 1988 passa a considerar crime contra o patrimônio a destruição ou deterioração causada aos arquivos. Nesse sentido, foi-se produzindo lentamente uma distinção do conceito de patrimônio como instrumento privado para tornar-se uma interpretação com sentido público e universal.

\section{MÉTODOS}

Os métodos adotados nesta pesquisa são norteados no conceito de educação patrimonial, que, segundo Horta; Grunberg; Monteiro (1999),

é um instrumento de "alfabetização cultural" que possibilita ao indivíduo fazer a leitura do mundo que o rodeia, lavando-o à compreensão do universo sociocultural e da trajetória histórico-temporal em que está inserido. Este processo leva ao reforço da autoestima dos indivíduos e comunidades e à valorização da cultura brasileira, compreendida como múltipla e plural. 
Trata-se de metodologia que consiste em processos permanentes e sistemáticos de trabalho educativo, com capacidade para gerar conhecimentos e descobertas, tendo como objeto o patrimônio cultural, com todas as suas manifestações (GRUNBERG, 2007). Os professores como disseminadores destes conhecimentos e conceitos podem colaborar para identificação das potencialidades e carências no desenvolvimento do processo de educação patrimonial [...] (GAZZÓLA, 2009).

Para alcançar os objetivos desta pesquisa, o projeto Clic@r Itapina utilizouse das técnicas de observação, registro, exploração (análise do bem cultural) e apropriação (releitura do bem cultural), conceituadas por Grunberg (2007), como base de seus procedimentos metodológicos.

A primeira etapa do projeto consistiu no planejamento e elaboração de um plano de ação. Em seguida, a equipe firmou parcerias com instituições públicas e privadas, de âmbito estadual e regional, visando conseguir apoio para o desenvolvimento das ações. A terceira foi a realização das oficinas de educação patrimonial, com carga horária de 40 horas, compostas de palestras, aulas teóricas e atividades práticas, que ocorreram em cinco encontros, entre os meses de fevereiro e maio, na EMEF Maria Ortiz, em Itapina, abordando os temas centrais de patrimônio cultural e fotografia. A etapa final foi a exposição fotográfica, que foi resultado das oficinas.

Durante as oficinas, após a abordagem teórica sobre patrimônio cultural e fotografia, foram desenvolvidas atividades práticas com o desafio inicial de constituir um acervo fotográfico composto por acervos pessoais e familiares oriundos da comunidade. Paralelamente a isso, os oficinandos também produziram registros fotográficos inéditos e atuais. Constituído o acervo fotográfico, as atividades das oficinas desdobraram-se na descrição arquivística das fotografias, sob os olhares dos oficinandos, com a formação de um banco de imagens sob a forma de blog $<$ www.clicaritapina.blogspot.com.br>.

A constituição do acervo fotográfico do projeto deu-se com a coleta de dados em arquivos pessoais/familiares, bem como em pesquisas em centros de memória e arquivos institucionais, além de fotografias inéditas produzidas pelos oficinandos. Para o detalhamento dos registros fotográficos, utilizou-se fichas de descrição e entrevistas com moradores, realizado pelo projeto e pelos participantes.

A avaliação das ações do projeto ocorreu por meio de observações, enquetes, questionários e fichas de avaliação. Os alunos foram avaliados pelo coordenador pedagógico do projeto por meio de participação e realização das atividades propostas, enquanto a oficina do projeto foi avaliada pelos alunos com a aplicação de questionário. Para responder o problema desta pesquisa, utilizou-se os dados estatísticos do blog do projeto, como análises quantitativas e a observação das reações manifestadas pela comunidade como fontes de informação qualitativa. 


\section{RESULTADOS}

O projeto Clic@r Itapina, por meio da oficina de educação patrimonial, formou 15 (quinze) participantes, realizando atividades teóricas e práticas, palestras, exposição fotográfica e interação com a comunidade. Os participantes que compõem o seleto grupo atuam como professores, estudantes ou pesquisadores e poderão atuar como disseminadores do conhecimento. Nesse sentido, espera-se que, também indiretamente, os objetivos do projeto possam ser alcançados.

Durante os dias 20/02 a 07/05/2016, em cinco encontros, o Projeto Clic@r Itapina realizou gratuitamente, na EMEF Maria Ortiz, localizada no distrito de Itapina, a oficina de educação patrimonial com ênfase em registros fotográficos pessoais e familiares. A oficina recebeu 40 (quarenta) inscrições, sendo que desse total 15 (quinze) participantes a concluíram com aproveitamento satisfatório.

$\mathrm{Na}$ avaliação pedagógica do projeto, aplicou-se um questionário com 13 perguntas, que foi respondido por 14 oficinandos e foram apurados os seguintes resultados:

1) A oficina foi fornecida conforme o prometido.

85,7\% concordaram plenamente;

14,3\% concordaram parcialmente.

2) As instalações físicas utilizadas durante a oficina foram adequadas.

28,6\% concordaram plenamente;

$71,4 \%$ concordaram parcialmente.

3) Os recursos tecnológicos utilizados durante a oficina foram adequados.

$57,1 \%$ concordaram plenamente;

42,9\% concordaram parcialmente.

4) $O$ conteúdo do blog foi compatível com as atividades da oficina.

$71,4 \%$ concordaram plenamente;

28,6\% concordaram parcialmente.

5) Os facilitadores da oficina foram claros e objetivos ao apresentar o conteúdo

e conduzir a oficina.

100\% concordaram plenamente.

6) Os facilitadores apresentaram domínio sobre o tema da oficina.

$85,7 \%$ concordaram plenamente;

14,3\% concordaram parcialmente.

7) Os facilitadores demonstraram entender as necessidades dos participantes da oficina.

$71,4 \%$ concordaram plenamente; 28,6\% concordaram parcialmente.

8) A oficina teve uma dinâmica participativa. 100\% concordaram plenamente.

9) A carga horária foi adequada para o desenvolvimento da oficina. $57,1 \%$ concordaram plenamente; 
28,6\% concordaram parcialmente;

$14,3 \%$ nem concordaram e nem discordaram.

10) A oficina atendeu às suas necessidades de aprendizagem e formação.

$57,1 \%$ concordaram plenamente;

42,9\% concordaram parcialmente.

11) O conteúdo disponibilizado durante a oficina vai impactar na sua forma de atuação profissional daqui para frente.

$71,4 \%$ concordaram plenamente; $28,6 \%$ concordaram parcialmente.

12) No geral, a oficina foi uma experiência positiva que pode gerar frutos.

100\% concordaram plenamente.

13) Eu recomendaria a oficina para possíveis interessados.

100\% concordaram plenamente.

De modo geral, a oficina e os facilitadores foram bem avaliados pelos oficinandos, que poderão replicar o aprendizado nas escolas onde atuam e na própria comunidade de Itapina. Ressalta-se que no dia 19/03/2016 o projeto contou com a presença de 20 (vinte) alunos do curso de Arquivologia da UFES, que se juntaram aos participantes da oficina e realizaram a atividade de campo denominada "Imaginando Itapina", que consistiu em aula com conteúdo teórico; aula de campo para produção de registros documentais fotográficos inéditos; discussão e consolidação dos conceitos de patrimônio cultural e descrição arquivística.

O projeto também fez parte do evento Itapina Cultural, realizado pela SECULT-ES, no dia 09/04/2016, por ocasião do $4^{\circ}$ encontro da oficina e palestra ministrada no Museu Virgínia Tamanini. Um dia antes, realizou-se uma ação conjunta entre Projeto Clic@r Itapina, Arquivo Público do Estado do Espírito Santo (APEES) e EMEF Maria Ortiz. Foram realizadas atividades de digitalização e descrição das fotografias das famílias dos alunos, elaboração de árvores genealógicas e emissão de certificados de entrada de imigrantes, por meio do Projeto Imigrante, através do Arquivo Itinerante do Arquivo Público do Estado do Espírito Santo.

Além de pesquisas documentais, a equipe do projeto realizou um trabalho de observação e interação com a comunidade para conhecer o contexto e as necessidades locais. Nesse ínterim, tivemos acesso a um registro fotográfico emblemático que retrata um momento do cotidiano de dois moradores de Itapina, que deu origem ao título da exposição fotográfica: Uma canoa chamada lembrança.

A exposição fotográfica teve seu lançamento no dia 25/05/2016 por ocasião do evento Fenaviola que recebe milhares de visitantes no sítio histórico e ficou aberta à visitação até o dia 28/05/2016, de 10h:00 às 20h:00, no Museu Virgínia Tamanini. A exposição itinerante ficou na EMEF Maria Ortiz de 30/05 a 10/06/2016, na Casa da Cultura de Colatina, de 13/06 a 22/07/2016 e na Biblioteca Central da UFES, de 25/07/2016 a 09/09/2016.

Por convite da Coordenação do "V Encontro de Documentação Audiovisual, Iconográfica, Sonora e Musical", o projeto foi apresentado em nível nacional por meio de palestra ministrada no "VII Congresso Nacional de Arquivologia", realizado 
durante os dias 17 a 21/10/2016, em Fortaleza-CE, com o seguinte título: "Fotografia e educação patrimonial: o Projeto Clic@r Itapina e o resgate da memória local”.

Como produtos do projeto, além da exposição fotográfica, foram confeccionados e distribuídos 2.000 folders, 4.000 cartões postais e 80 camisas do projeto. A página no Facebook foi utilizada como meio de aprendizado, sendo o local virtual onde os oficinandos postavam suas atividades. Criado em novembro de 2015, o blog do projeto foi (ainda é) fonte confiável de avaliação estatística do projeto e dele foram extraídos, no dia 04/04/2017, os seguintes dados:

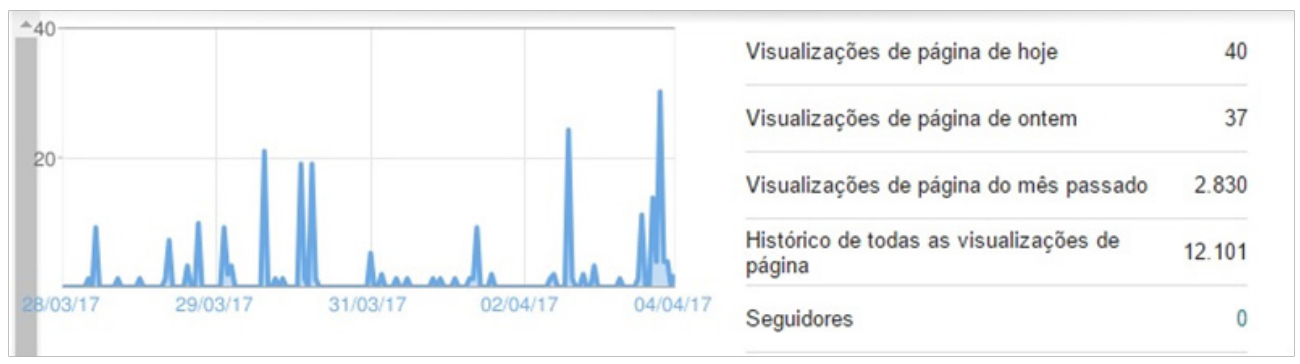

Verifica-se que em 17 meses o blog teve 12.101 visualizações, sendo que no mês anterior foram 2.830 e que nos dois últimos dias obteve uma média de 38,5 visualizações. Considerando o total de visualizações, desde sua publicação, apurouse a média de 711,82 visualizações mensais, fato considerado positivo no sentido de divulgação e valorização do patrimônio cultural de Itapina.

A análise dessas visualizações pode ser expandida em nível mundial, como se verifica na tabela a seguir.

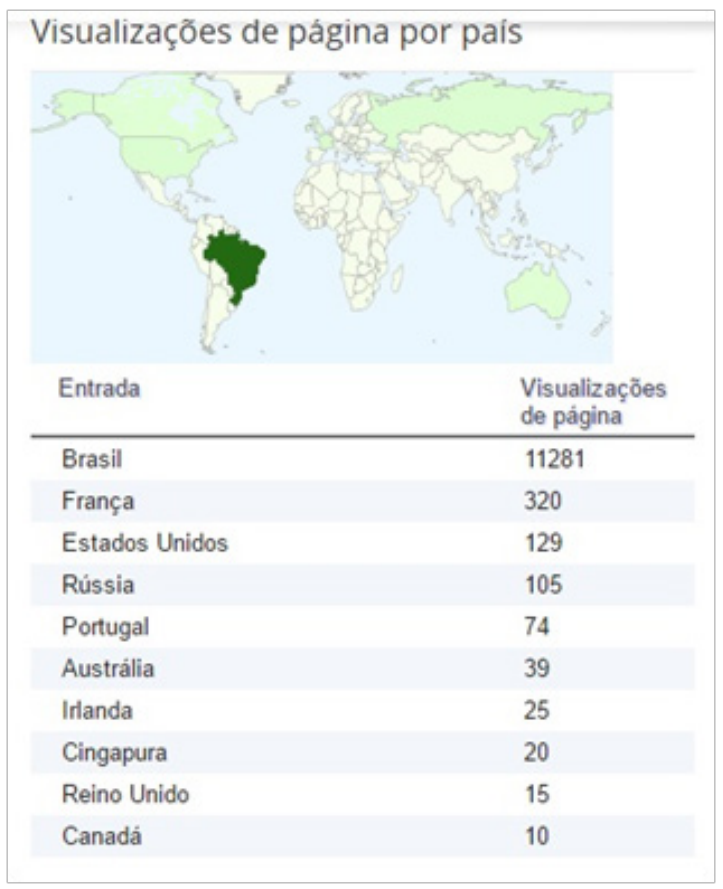


Verifica-se que 93,22\% visualizações ao blog foram oriundos do território brasileiro, seguidos de 320 acessos da França, 129 dos Estados Unidos e 105 da Rússia, dentre outros países. Infelizmente, o aplicativo estatístico do blog não permite quantificar estas visualizações por estados, mas entendemos como resultado positivo este alcance internacional.

Outra análise estatística diz respeito ao tipo de informação mais acessado no blog, conforme demonstração na tabela a seguir:

\begin{tabular}{|c|c|c|}
\hline \multicolumn{3}{|l|}{ Postagens } \\
\hline Entrasa & $\begin{array}{l}\text { Vsualcaples de } \\
\text { pagins }\end{array}$ & \\
\hline $\begin{array}{l}\text { REGISTRO N } 112 \text { LEGENDE: Aniv. } \\
12 \text { de jun de } 2010\end{array}$ & 075 & 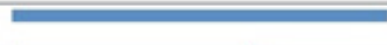 \\
\hline $\begin{array}{l}\text { REGISTRO N } 118 \text { LEGENDA: bapi- } \\
3 \text { de } 290 \text { de } 2010\end{array}$ & 637 & 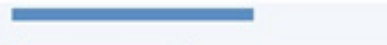 \\
\hline $\begin{array}{l}\text { REOISTRO Ne HOLEGENDA. PIOC. } \\
12 \text { de jun de } 2010\end{array}$ & 458 & 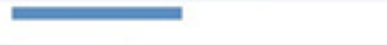 \\
\hline $\begin{array}{l}\text { REGISTRO NE :OLLEGENDA: A Es } \\
1164 \text { jon } 6 * 2016\end{array}$ & 311 & $=$ \\
\hline $\begin{array}{l}\text { REGISTRO N } 106 L \text { EGENDA DOn. } \\
11 \text { de jon } \delta * 2016\end{array}$ & 170 & $=$ \\
\hline $\begin{array}{l}\text { REGISTRO N O2LEGENDA: Fand. } \\
11 \text { de jun de } 2016\end{array}$ & 113 & $=$ \\
\hline $\begin{array}{l}\text { PEGISTRO N } 111 \text { LEGENDA. Priet. } \\
1264 \text { jun de } 2016\end{array}$ & 107 & 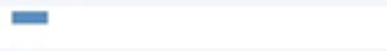 \\
\hline 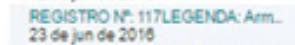 & 105 & $=$ \\
\hline $\begin{array}{l}\text { REGISTRO NE: } 120 \text { LEGENOA Um. } \\
3 \text { St } 390 \text { Se } 2010\end{array}$ & 47 & $\mathbf{a}$ \\
\hline $\begin{array}{l}\text { REGISTRO N : 110LEGENDA: Dion } \\
12 \text { de jun de } 2010\end{array}$ & 47 & $\mathbf{a}$ \\
\hline \multicolumn{3}{|l|}{ Páginas } \\
\hline Entrada & $\begin{array}{l}\text { Vsualleaples de } \\
\text { pdgina }\end{array}$ & \\
\hline $\begin{array}{l}\text { tapina } \\
126+\text { jun } d t 2010\end{array}$ & 738 & 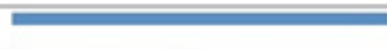 \\
\hline $\begin{array}{l}\text { Oprojeb } \\
2 \text { Se dez de } 2015\end{array}$ & 325 & $=$ \\
\hline $\begin{array}{l}\text { Oficies } \\
24 \text { de fov de } 2010\end{array}$ & 220 & = \\
\hline $\begin{array}{l}\text { Inscriclis } \\
2 \delta_{4} \text { dez de } 2015\end{array}$ & 183 & $=$ \\
\hline $\begin{array}{l}\text { Biblograta } \\
3 \text { St maide } 2010\end{array}$ & 148 & = \\
\hline $\begin{array}{l}\text { Apois } \\
\text { 4de mai de } 2016\end{array}$ & 120 & $=$ \\
\hline $\begin{array}{l}\text { Contass } \\
\text { if de dez de 2015,6 comentíios }\end{array}$ & 126 & 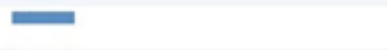 \\
\hline $\begin{array}{l}\text { Equipe } \\
20 \text { se }\end{array}$ & 117 & $=$ \\
\hline
\end{tabular}

Figura 1. Tabela 3: Postagens e páginas mais visitadas no BlogClic@r Itapina. Dados coletados em 04/04/2017.

Ao contrário do que se imagina os registros fotográficos mais acessados não se referem à conhecida ponte inacabada do distrito, mas sim a aspectos sociais. Com 975 visualizações, a festa de 15 anos da Sra Rosane Moratti (acervo pessoal dela) foi a mais acessada. Tal fotografia, registrada em 1974, tem como destaque a elegância dos vestidos da época. O segundo registro mais acessado, de autor e data desconhecidos, mostra os jogadores (a maioria deles identificados na imagem) do Itapinense Futebol Clube. O terceiro registro mais acessado é o de uma procissão da Igreja de N. Sra do Perpétuo Socorro, em Itapina, na década de 1960, do acervo pessoal da Família Castiglioni, no qual se verifica uma grande multidão com trajes da época, em especial os ternos.

Conforme os resultados apurados, verifica-se que o projeto Clic@r Itapina influenciou nos aspectos sociais do sítio histórico de Itapina, evidenciando sua 
história para o Espírito Santo, para o Brasil e para o Mundo, assim como para a comunidade acadêmica, aplicando uma metodologia diferente da convencional para se obter conhecimento e que serão discutidos a seguir.

\section{DISCUSSÃO / CONCLUSÃO}

O Projeto Clic@r Itapina foi realizado pelo grupo de pesquisa Arquivum, do Departamento de Arquivologia da UFES, com recursos do FUNCULTURA/SECULTES e beneficiou a comunidade de Itapina, estudantes universitários, professores e pesquisadores, promovendo impactos de suma importância ao provocar nos participantes o censo crítico e o espírito de colaborador quanto à preservação, proteção e valorização do patrimônio local, além de impulsionar o desenvolvimento local por meio de ações de educação patrimonial, utilizando a fotografia como linguagem artística para expressar as manifestações do patrimônio cultural do sítio histórico de Itapina, por meio do registro de seus bens materiais e imateriais em diferentes épocas, inclusive a atual. No período de execução, a equipe do projeto buscou proporcionar aos participantes e à comunidade de Itapina meios de compreensão de sua história e a importância de sua inserção nas ações de educação patrimonial.

A oficina Clic@r Itapina proporcionou a formação de multiplicadores com as seguintes capacidades: conhecimento do patrimônio cultural e seu ensino no processo de aprendizagem; ampliação a participação dos adolescentes, moradores e professores na localidade; assimilação de conteúdos e o uso das novas tecnologias no processo de ensino e aprendizagem.

O projeto de extensão universitária envolveu professores, alunos e a comunidade de Itapina. Na EMEF Maria Ortiz, os alunos foram instigados a investigar sobre os acervos pessoais, incluindo a participação de seus familiares no resgate da memória, além da elaboração de árvores genealógicas. Já os alunos do curso de Arquivologia da UFES participaram de um estudo de campo, no qual foi possível refletir sobre os conceitos de patrimônio cultural e realizar a atividade de uma das principais funções da disciplina: a descrição arquivística.

A criação de um banco de imagens com as fotografias identificadas através de conceitos e descritores facilitará o acesso e poderá ser utilizados como fonte de informações sobre o sítio histórico de Itapina, para professores, alunos, pesquisadores, profissionais da informação e comunidade em geral, gerando conhecimento e promovendo o resgate da memória.

Por meio do blog do projeto foi possível analisar dados estatísticos e verificou-se que aspectos socioculturais de Itapina chamaram a atenção de internautas no Brasil e no mundo, com uma média de 711,82 visualizações mensais, que podem ser traduzidas em valorização da cultura local.

Como resultado da oficina de educação patrimonial, a exposição fotográfica "Uma canoa chamada lembrança" foi realizada com a participação da comunidade, fato que promoveu a sensação de pertencimento e foram vários os comentários de satisfação e emoção das pessoas que se sentiram parte da história de Itapina. Há 
relatos de pessoas que vieram de Vitória, Vila Velha, Colatina, Linhares, Baixo Guandu, especialmente para ver a exposição e a homenagem prestada à comunidade de Itapina.

Na fotografia principal, que deu nome à exposição, a bela moça Adélia e o menino Jaime, retratam um momento do cotidiano de dois moradores, que nos remetem à relação que a comunidade mantinha com o Rio Doce. Declarando-se muito emocionada, a filha da dona Adélia (in memoriam) agradeceu aos coordenadores do projeto e disse que "o céu está em festa nesta data, pois minha mãe era muito vaidosa e certamente está muito feliz com esta homenagem”. Depoimentos como este só podem ser obtidos e mensurados na prática, na interação com a comunidade. De modo geral, foi muito gratificante vivenciar um dos principais objetivos do Projeto Clic@r Itapina sendo alcançado: a comunidade de Itapina externando o valor afetivo pelos seus bens culturais, identificando-se e sentindo-se parte da história local.

O resultado final, após a oficina de educação patrimonial e os produtos dela resultantes, foi positivo e a comunidade manifestou-se pela continuidade do projeto, comprometendo-se com a doação de novas imagens dos acervos pessoais. Diante de uma manifestação dessas, espera-se que esse projeto possa estimular a proposição e execução de outros, que venham impulsionar o desenvolvimento cultural, social e econômico de Itapina.

Em resposta ao problema da pesquisa, conclui-se que a metodologia de educação patrimonial aplicada pela equipe do projeto Clic@r Itapina foi eficiente para o propósito de despertar o sentimento de pertencimento e foi uma forma de valorizar a cultura local. Entendemos que a hipótese também foi confirmada, pois quanto mais se disponibilizou o acesso às fotografias, mais sentimentos afetivos foram despertados, trazendo boas lembranças.

Nesse sentido, a análise final é de que o conteúdo informacional das fotografias remeteu ao sentimento de pertencimento e à valorização do patrimônio cultural do sítio histórico de Itapina. A educação patrimonial atual é uma condição sine qua non para envolver a rede escolar, a comunidade local e tantos outros cidadãos que desconhecem o principal papel de seu patrimônio cultural e sua representatividade perante a história e a sociedade.

\section{REFERÊNCIAS}

[1] Castiglioni, L. A. Itapina: Trajetória de um vilarejo. Projeto de Graduação I do Curso de Arquitetura e Urbanismo (UFES). Vitória: 2010.

[2] Cruz Mundet, J. R. Manual de archivística. 4. ed. Madrid: Fundación G. Sanchez, 2001. ESPÍRITO SANTO. Secretaria de Estado da Cultura. Resolução CEC n003/2013. Disponível em: <http://secult. es.gov.br/_midias/pdf/resolucao_tombamento_itapina-8969-52b2e43b16cb0.pdf>. Acesso em 20/02/2017.

[3] Fonseca, M. C. L. Para Além da pedra e do cal: por uma concepção ampla de patrimônio Cultural. In: ABREU, R. C. M. Memória e Patrimônio: ensaios contemporâneos. Rio de Janeiro: DP\&A, 2003. pp. 65-80.

[4] Gazzóla, L. Educação patrimonial: teoria e prática. III Encontro Sul Brasileiro de Psicopedagogia. In IX Congresso Nacional de Educação (EDUCERE). 2009. 
[5] Grunberg, E. Manual de atividades práticas de educação patrimonial. Brasília, DF : IPHAN, 2007.

[6] Horta, M. L. P.; Grunberg, E.; Monteiro, A. Q. Guia Básico de Educação Patrimonial. Brasília: Instituto do Patrimônio Histórico e Artístico Nacional / Museu Imperial, 1999.

[7] Instituto Do Patrimônio Histórico E Artístico Nacional (Iphan). Superintendência do Iphan na Paraíba. Educação patrimonial: educação, memórias e identidades; Átila Bezerra Tolentino (Org.). - (Caderno Temático; 3). João Pessoa: Iphan, 2013.

[8] Mattar, E. Dos arquivos em defesa do Estado ao Estado em defesa dos arquivos. In: MATTAR, E. (org.). Acesso à informação e política de arquivos. Rio de Janeiro: Arquivo Nacional, 2003. pp.15-26.

[9] Weber, M. Ensaios de Sociologia. Rio de Janeiro: Guanabara Koogan, 1982.

\section{AGRADECIMENTOS}

Projeto realizado com recursos financeiros do Fundo de Cultura (Funcultura); Secretaria de Estado da Cultura (Secult-ES) e suporte acadêmico do Grupo de Pesquisa do CNPq Arquivum. 


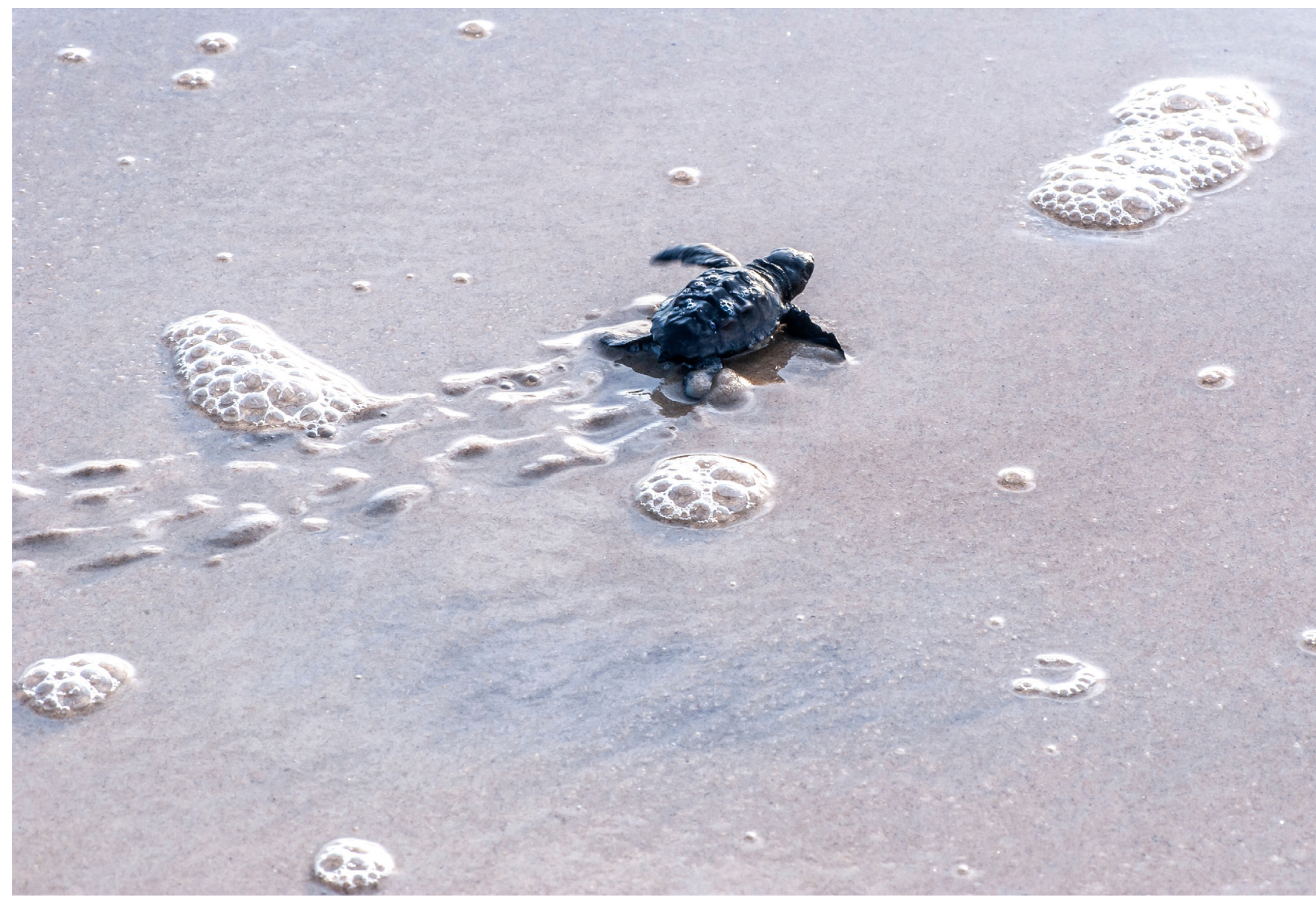

